\title{
Copolymers of Glycidyl Methacrylate with 3-Methylthienyl Methacrylate: Synthesis, Characterization and Reactivity Ratios
}

\author{
Okan GUNAYDIN and Faruk YILMAZ ${ }^{\dagger}$ \\ Department of Chemistry, Gebze Institute of Technology, 41400 Gebze, Kocaeli, Turkey
}

(Received December 1, 2006; Accepted March 12, 2007; Published April 23, 2007)

\begin{abstract}
Homo-polymers of glycidyl methacrylate (GMA) and 3-methylthienyl methacrylate (MTM) and their copolymers in various compositions were prepared by free radical polymerization in dimethyl formaldehyde (DMF) solution at $60^{\circ} \mathrm{C}$ using $\alpha, \alpha^{\prime}$-azobisisobutyronitrile (AIBN) as an initiatior. The copolymers, poly(GMA-coMTM), were characterized by ${ }^{1} \mathrm{H}$ NMR and ${ }^{13} \mathrm{C}$ NMR spectroscopic techniques. ${ }^{1} \mathrm{H}$ NMR analysis was used to determine the copolymer compositions. The molecular weights $\left(M_{\mathrm{w}}\right.$ and $\left.M_{\mathrm{n}}\right)$ and polydispersity indices of the copolymers were determined by gel permeation chromatography (GPC). Thermal behavior of the copolymers was also investigated by thermogravimetrical analysis (TGA) and differential scanning calorimetry (DSC). Monomer reactivity ratios were determined for low conversion using Fineman Ross $(\mathrm{FR})\left(r_{\mathrm{GMA}}=0.9795 ; r_{\mathrm{MTM}}=0.5641\right)$ and Kelen Tüdós (KT) $\left(r_{\mathrm{GMA}}=0.9796 ; r_{\mathrm{MTM}}=0.5771\right)$ graphical methods. In both cases, $r_{1} r_{2}$ is less than 1 , indicating that the copolymer deviates slightly from ideal copolymerization. [doi:10.1295/polymj.PJ2006180]

KEY WORDS Glycidyl Methacrylate / 3-Methylthienyl Methacrylate / Fineman Ross / Kelen Tüdós / Reactivity Ratios /
\end{abstract}

As a new class of materials, intrinsically conductive polymers (ICPs) have been the focus of intense research in scientific community due to the their wide range of potential use in many applications such as light emiting diodes, ${ }^{1}$ batteries, ${ }^{2}$ electrochromic devices, ${ }^{3-6}$ sensors, ${ }^{7}$ electromagnetic shielding, ${ }^{8}$ and corrosion inhibition. ${ }^{9}$

Polythiophenes (PThs) have received a great deal of attention among ICPs because of its electrical properties, environmental stability in doped and undoped states, non-linear optical properties, and highly reversible redox switching. ${ }^{10}$ As thiophene has a rich synthetic flexibility, allowing for the use of several polymerization methods and the incorporation of various side chain functionalities, PThs have become the most widely studied of all conjugated polyheterocycles. ${ }^{11-13}$

However, the most commonly faced problem in conducting polymers is the poor mechanical properties, which create processing problems and thus limit their applications. Various methods such as introduction of alkyl groups into the main chain, synthesis of soluble precursors, and preparation of conducting polymer composites, blends, and copolymers can be used to improve mechanical and physical properties. ${ }^{14,15}$

In previous works, ${ }^{16-18}$ we performed the synthesis of thiophene-functionalized methacrylate monomer, namely 3-thienylmethyl methacrylate (MTM) via the esterification of 3-thiophene methanol with methacryloyl chloride. Then, it was used in the preparation of block and random copolymers with methyl methacrylate (MMA) and liquid crystalline monomer, 6-(4cyanobiphenyl-4'-oxy)hexyl acrylate. Subsequently, the graft copolymers of the side chain thiophene containing polymers with polypyrrolle and polythiophene were synthesized by constant-potential electrolyses.

Copolymerization is the most successful and powerful one among the existing polymerization methods for effecting systematic changes in polymer properties since it does not demand rigorous experimental conditions and can be applied to a large variety of monomers, leading to the formation of new materials. ${ }^{19}$ In the study of copolymerizations, monomer reactivity ratio is the major concern to predict the copolymer composition for any starting feed and to understand the kinetic and mechanistic aspects of copolymerization and the correlation between structure and properties. ${ }^{1} \mathrm{H}$ NMR technique has been established as a powerful tool for the determination of tacticity and sequence distribution as well as for the estimation of copolymer composition because of its simplicity, rapidity, and sensitivity. ${ }^{20,21}$ Incorporation of acrylates and methcrylates monomers bearing reactive functional pendant groups into polymers provides a versatile route for the preparation of reactive polymers. ${ }^{22-24}$ Copolymers of GMA, an epoxy group containing methacrylate monomer, with other acrylic or vinyl monomers have received significant attention due to the pendant epoxide groups. This is because, it enters into a large number of chemical reactions by oxirane

${ }^{\dagger}$ To whom correspondence should be addressed (Tel: +90 26260531 33, Fax: +90 26260531 05, E-mail: fyilmaz@gyte.edu.tr). 
ring opening, thus offering the opportunity for chemical modification of the pendant copolymers for various applications such as immobilization of enzymes, DNA, catalysts, and biomolecules. ${ }^{25,26}$

In this work, the copolymers of GMA and MTM were prepared in DMF by varying the molar ratios of the monomers in the feed. ${ }^{1} \mathrm{H}$ NMR analysis was employed for determination of the copolymer compositions. Graphical methods were used to find the reactivity ratios of the comonomers. Thermal properties of all the polymers were analyzed by thermogravimetric analysis (TGA) and differential scanning calorimetry (DSC).

\section{EXPERIMENTAL}

\section{Materials}

Commercial solvents were purified according to usual procedures. Dichloromethane $\left(\mathrm{CH}_{2} \mathrm{Cl}_{2}\right)$ was first extracted with sulfuric acid, washed with water, then extracted with 5\% $\mathrm{NaOH}$ solution, and again washed with water. It was then dried over calcium chloride and fractionally distilled. Glycidyl methacrylate (GMA) (Fluka) was purified by distillation under reduced pressure. 3-Thienylmethyl methacrylate (MTM) was synthesized according to literature procedure. ${ }^{16,17}$ AIBN $\left(\alpha, \alpha^{\prime}\right.$-azobisisobutyronitrile $)$ was purified by recrystallization from methanol. All other reagents were purchased from Aldrich and used as received.

\section{Synthesis of Co-polymers (poly(GMA-co-MTM))}

Predetermined quantities of MTM, GMA, dimethylformaldehyde (DMF) and AIBN (1\% of total weight of monomers) were placed in a Pyrex tube. The mixture was deoxygenated by flushing with $\mathrm{O}_{2}$-free argon for at least $10 \mathrm{~min}$. The tube was tightly sealed and immersed in a thermostated oil bath at $60 \pm 1{ }^{\circ} \mathrm{C}$. The reaction time was selected to give conversions up to $13 \mathrm{wt} \%$ in order to satisfy the differential copolymerization equation. The conversions were controlled and determined by gravimetric measurements. After the reaction times, the copolymers were precipitated in methanol, filtered off, and purified by reprecipitations from dichloromethane solution into methanol and finally dried in vacuo at $24 \mathrm{~h}$.

\section{Characterization}

${ }^{1} \mathrm{H}$ and ${ }^{13} \mathrm{C}$ NMR spectra were taken on $500 \mathrm{MHz}$ NMR (varian) spectrometer using $\mathrm{CDCl}_{3}$ as the solvent at room temperature. Molecular weights and molecular weight distributions of the polymers were measured on an Agilent Instrument (Model 1100) consisting of a pump, refractive index and UV detectors, and four Water Styragel columns (HR 5E, HR 4E, HR
3, and HR 2) and using THF as eluent at a flow rate of $0.3 \mathrm{~mL} / \mathrm{min}$ at $30^{\circ} \mathrm{C}$ and toluene as an internal standard. Molecular weights were calculated with the aid of polystyrene standards. DSC thermograms of the copolymers were investigated via a METTLER TOLEDO. The samples of 5-10 mg were used with a $10^{\circ} \mathrm{C} / \mathrm{min}$ heating/cooling rate in nitrogen. The $T_{\mathrm{g}}$ is the midpoint in the heat-capacity change. Thermo gravimetric data were obtained by using a METTLER TOLEDO TGA/SDTA851 $1^{\mathrm{e}}$ thermal analyzer on 2$5 \mathrm{mg}$ samples at $10^{\circ} \mathrm{C} / \mathrm{min}$ from 25 to $700^{\circ} \mathrm{C}$ under nitrogen flow.

\section{RESULTS AND DISCUSSION}

\section{Homo-polymers}

Homo-polymers PGMA and PMTM were prepared by a typical free radical polymerization with AIBN as an initiator. Figure $1 \mathrm{a}$ and $\mathrm{b}$ portray the ${ }^{1} \mathrm{H}$ NMR spectra of PGMA and PMTM, respectively. In the ${ }^{1} \mathrm{H}$ NMR spectrum of PGMA, the signals at around $2.65-3.25 \mathrm{ppm}$ and $3.82-4.30 \mathrm{ppm}$ are assigned to the protons of epoxy ring and those connected to the epoxy ring $\left(\mathrm{COOCH}_{2}\right)$, respectively. As for the spectrum of PMTM, the peaks in the range of 6.80$7.31 \mathrm{ppm}$ are attributed to the protons of the thiophene ring. The peak at $4.85 \mathrm{ppm}$ originates from methylene protons adjacent to thiophene ring $\left(\mathrm{ThCH}_{2}\right)$. The broad resonance signals at both spectra (in the range of 1.0 and $2.0 \mathrm{ppm}$ ) are due to the backbone methylene and the $\alpha$-methyl groups. GPC analysis revealed the formation of unimodal homopolymers with the characteristic polydisperties obtained in the conventional free radical polymerization.

\section{Co-polymers}

The copolymers, poly(GMA-co-MTM), were synthesized via radical polymerization of appropriate GMA/MTM feed mixtures of different chemical compositions in the presence of AIBN as an initiator (Scheme 1). The structure of the copolymers was characterized by means of ${ }^{1} \mathrm{H}$ and ${ }^{13} \mathrm{C}$ NMR spectroscopy. The ${ }^{1} \mathrm{H}$ NMR spectrum of poly $\left(\mathrm{GMA}_{59}-\mathrm{co}-\right.$ $\mathrm{MTM}_{41}$, copolymer 4 in Table I) obtained from a comonomer mixture with a feed ratio of [GMA]/ $[\mathrm{MTM}]=1.15$ is shown in Figure 1c. The chemical shift assignments of the copolymers were based on those obtained for PGMA and PMTM.

Figure 2 shows the proton decoupled ${ }^{13} \mathrm{C}$ NMR spectrum of poly $\left(\mathrm{GMA}_{59}-\mathrm{co}-\mathrm{MTM}_{41}\right)$. The resonance signals at 176.44 and $177.93 \mathrm{ppm}$ are due to the ester carbonyl carbons of GMA and MTM units, respectively. The signals of the carbon atoms of the thiophene ring are observed at $125.09 \mathrm{ppm}\left(\mathrm{C}_{16}\right), 126.40$ ppm $\left(\mathrm{C}_{15}\right), 126.42 \mathrm{ppm}\left(\mathrm{C}_{14}\right)$, and $136.15 \mathrm{ppm}\left(\mathrm{C}_{13}\right)$. 
a)
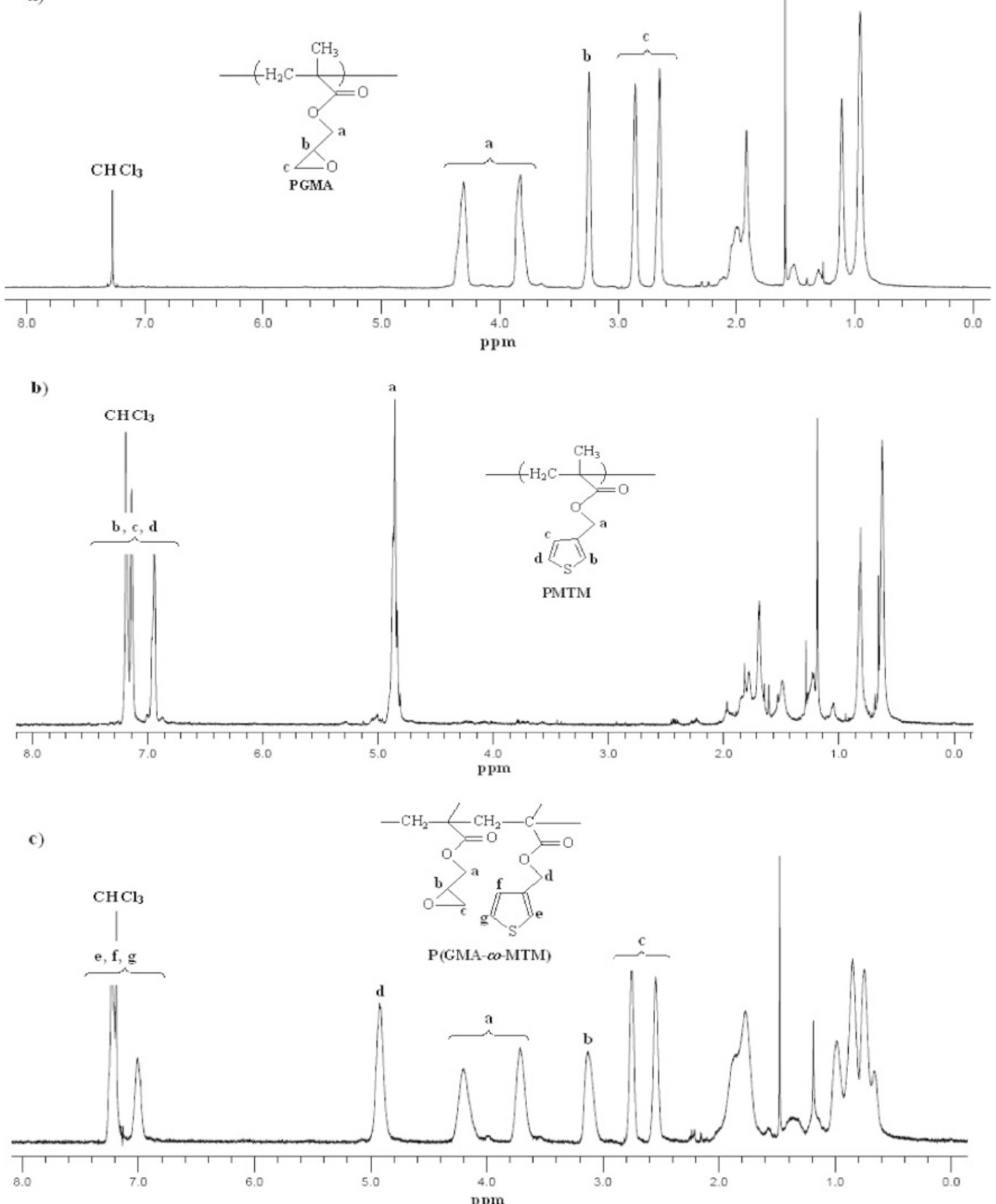

Figure 1. ${ }^{1} \mathrm{H}$ NMR spectra (solvent, $\mathrm{CDCl}_{3}$; at rt) of poly(GMA) (a); poly(MTM) (b) and poly $\left(\mathrm{GMA}_{59}\right.$-co-MTM 41 ) (c) (copolymer 4 in Table I).

The methyne and methylene carbon atoms of the epoxy ring give signals at $49.04 \mathrm{ppm}\left(\mathrm{C}_{6}\right), 54.28 \mathrm{ppm}$ $\left(\mathrm{C}_{7}\right)$. The methylene carbon atom, due to its symmetry, is sensitive to tacticity. The small peak appearing around at $52 \mathrm{ppm}$ is attributable to stereochemical configuration of monomeric units along the polymer chain. The methylene carbons $\left(\mathrm{C}_{5}\right.$ and $\left.\mathrm{C}_{12}\right)$ attached to the epoxy and thiophene rings show signals at
62.04 and $66.05 \mathrm{ppm}$, respectively. The signals due to the backbone methylene and tertiary carbon atoms are observed at $44-45 \mathrm{ppm}$. The $\alpha$-methyl group of both GMA and MTM monomers show resonances at 16-19 ppm.

The assignment of the resonance peaks of each kind of monomeric unit in the copolymer chains leads to the accurate evaluation of the composition of copoly- 
mers. Thus, the composition of copolymers was calculated by comparing the integral peak areas of the methylene protons $\left(-\mathrm{COOCH}_{2}-\right)(\mathbf{d})$, exhibiting resonance signal at around at $5.0 \mathrm{pmm}$, to that of the methyne proton of epoxy ring (b) showing signal at about $3.1 \mathrm{ppm}$ (Figure 1c).

The following expression is used to calculate the composition of copolymers. Let $\mathrm{x}$ be the mole fraction of MTM and $(1-\mathrm{x})$ be that of GMA. From eq 1, the mole fractions of MTM were determined by measur-

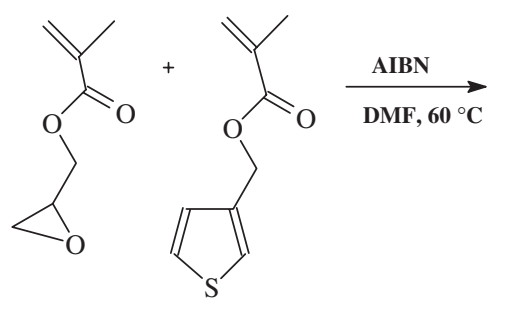

GMA

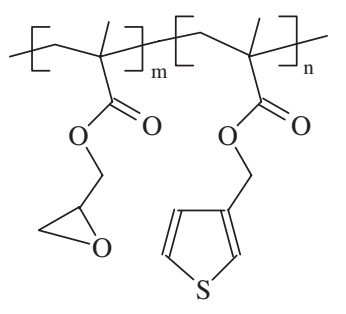

P(GMA-co-MTM)
Scheme 1. Synthesis of poly(GMA-co-MTM). ing the intensities of the corresponding aliphatic proton signals. The values of $\mathrm{C}$ and the corresponding mole fractions are given in Table I. The plot of mole fractions of GMA in the copolymer $\left(m_{\mathrm{GMA}}\right) v s$ that in the feed $\left(M_{\mathrm{GMA}}\right)$ is also shown in Figure 3. As can be seen, the composition of GMA units in the copolymers increased slightly with increasing amount of GMA monomer in the feed.

$$
\mathrm{C}=\frac{\text { Area of protons }(\mathbf{d}) \text { at } 4.8-5.0 \mathrm{ppm}}{\text { Area of protons }(\mathbf{b}) \text { at } 3.0-3.2 \mathrm{ppm}}=\frac{2 \mathrm{x}}{(1-\mathrm{x})}
$$

The number and weight average molecular weights of PGMA, PMTM and the copolymers were estimated by gel permeation chromatography and are presented in Table II. Unimodal copolymers with polydispersities in the range of 2.08-2.73, which is the typical of the conventional free radical polymerization, were obtained. If the polymerization is stopped at low conversion, the polydispersity index, i.e., the ratio of the weight average molecular weight to the number

Table I. Composition data for free-radical copolymerization of GMA with MTM

\begin{tabular}{|c|c|c|c|c|c|c|c|}
\hline \multirow{2}{*}{$\begin{array}{c}\text { Copolymer } \\
\text { P(GMA-co-MTM) }\end{array}$} & \multirow[t]{2}{*}{$M_{\mathrm{GMA}}{ }^{\mathrm{a}}$} & \multirow{2}{*}{$\begin{array}{c}\text { Conversion } \\
(\%)\end{array}$} & \multicolumn{2}{|c|}{$\begin{array}{l}\text { Integrated peak } \\
\text { areas }\end{array}$} & \multirow[t]{2}{*}{$\mathrm{C}$} & \multirow[t]{2}{*}{$m_{\mathrm{GMA}}{ }^{\mathrm{a}}$} & \multirow[t]{2}{*}{$m_{\mathrm{MTM}}{ }^{\mathrm{c}}$} \\
\hline & & & $\mathrm{d}^{\mathrm{b}}$ & $\mathrm{b}^{\mathrm{b}}$ & & & \\
\hline 1 & 0.1412 & 9.2 & 4.11 & 0.61 & 6.74 & 0.2289 & 0.7711 \\
\hline 2 & 0.2772 & 10.1 & 3.35 & 0.86 & 3.90 & 0.3393 & 0.6607 \\
\hline 3 & 0.4177 & 10.0 & 3.12 & 1.29 & 2.42 & 0.4526 & 0.5474 \\
\hline 4 & 0.5350 & 11.3 & 2.11 & 1.53 & 1.38 & 0.5919 & 0.4081 \\
\hline 5 & 0.6573 & 12.8 & 1.12 & 1.19 & 0.94 & 0.6800 & 0.3200 \\
\hline 6 & 0.7754 & 7.2 & 0.90 & 1.87 & 0.48 & 0.8060 & 0.1940 \\
\hline 7 & 0.8895 & 7.9 & 0.57 & 2.34 & 0.24 & 0.8914 & 0.1086 \\
\hline
\end{tabular}

${ }^{\mathrm{a}} M_{\mathrm{GMA}}$ and $m_{\mathrm{GMA}}$ are the mole fraction of GMA in the feed and copolymer, respectively. ${ }^{\mathrm{b}} \mathbf{d}$ and $\mathbf{b}$ denote the methylene protons adjacent to thiophene ring and methyne proton of epoxy ring, respectively (Figure 1c). ${ }^{\mathrm{c}} m_{\mathrm{MTM}}$ is the mole fraction of MTM in the copolymer.

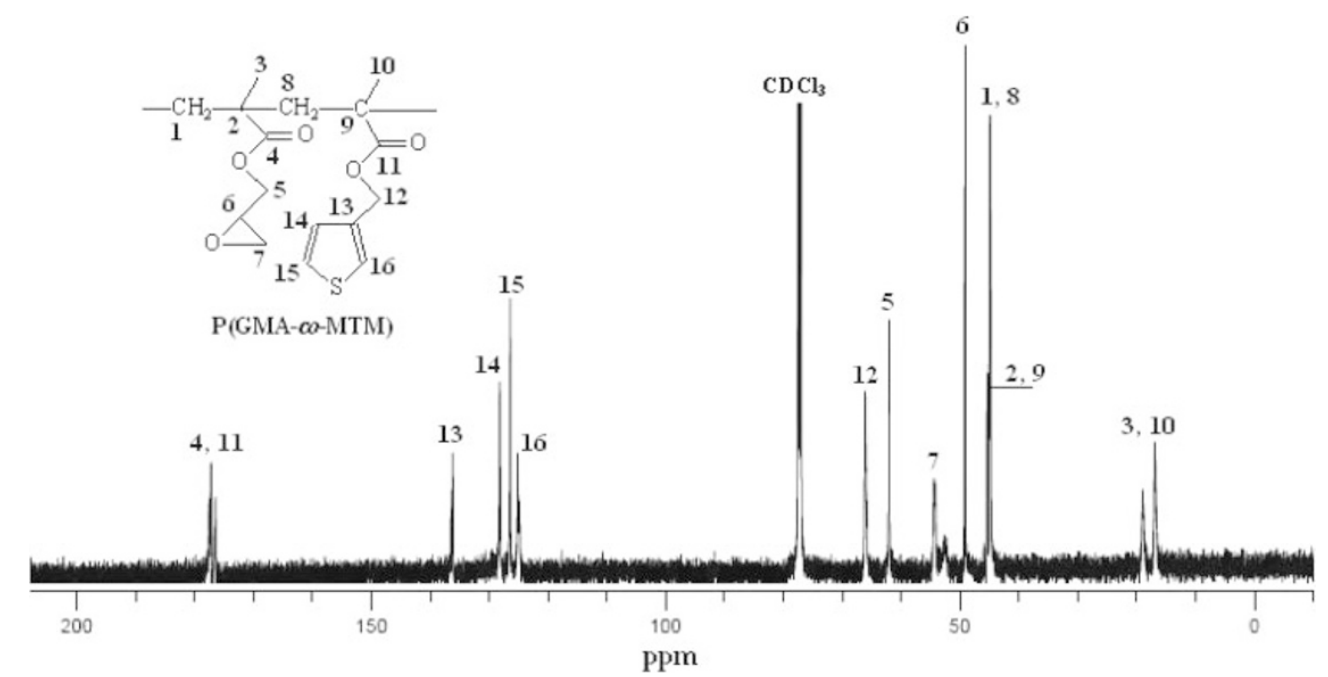

Figure 2. Proton-decoupled ${ }^{13} \mathrm{C}$ NMR spectrum (solvent, $\mathrm{CDCl}_{3}$; at rt) of poly $\left(\mathrm{GMA}_{59}\right.$-co-MTM $\mathrm{M}_{41}$ ) (copolymer 4 in Table I). 


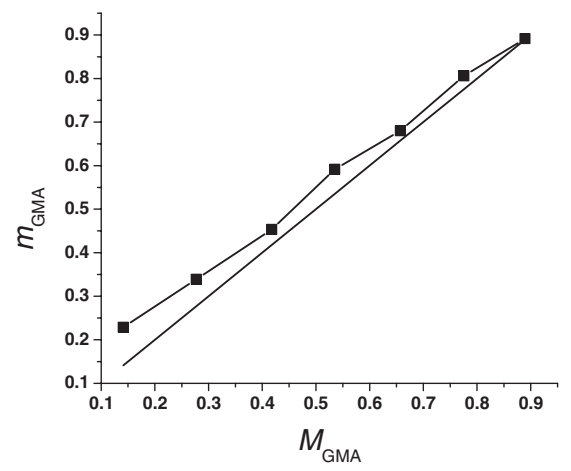

Figure 3. Feed vs copolymer composition curve.

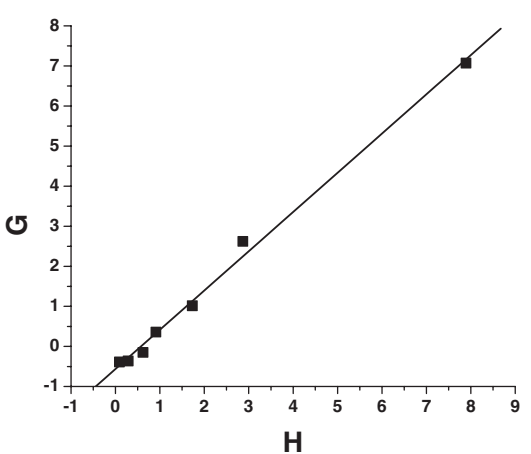

Figure 4. FR plot for GMA-MTM copolymer system.

Table II. Molecular weight data for homo and copolymers of GMA and MTM

\begin{tabular}{lccccc}
\hline \multicolumn{1}{c}{ Polymer } & $m_{\mathrm{GMA}}{ }^{\mathrm{a}}$ & $m_{\mathrm{MTM}}$ & $M_{\mathrm{w}} \times 10^{-3}$ & $M_{\mathrm{n}} \times 10^{-3}$ & $M_{\mathrm{w}} / M_{\mathrm{n}}$ \\
\hline PMTM & 0.0000 & 1.0000 & 86.0 & 37.7 & 2.29 \\
P(GMA-co-MTM) & 0.2289 & 0.7711 & 56.0 & 22.0 & 2.54 \\
& 0.3393 & 0.6607 & 123.9 & 50.8 & 2.43 \\
& 0.4526 & 0.5474 & 115.9 & 49.8 & 2.32 \\
& 0.5919 & 0.4081 & 132.5 & 48.4 & 2.73 \\
& 0.6800 & 0.3200 & 149.5 & 57.8 & 2.59 \\
PGMA & 0.8060 & 0.1940 & 196.0 & 94.0 & 2.08 \\
& 0.8914 & 0.1086 & 178.0 & 80.0 & 2.22 \\
& 1.0000 & 0.0000 & 137.2 & 52.7 & 2.60 \\
\hline
\end{tabular}

${ }^{\mathrm{a}} m_{\mathrm{GMA}}$ is the mole fraction of GMA in the copolymer.

average molecular weight $\left(M_{\mathrm{w}} / M_{\mathrm{n}}\right)$ is 2 and termination takes place by disproportionation. It is 1.5 in the case of termination by coupling. ${ }^{27}$ Therefore, the polydispersities of both homopolymers and copolymers strongly suggest chain termination by disproportionation.

\section{Monomer Reactivity Ratios}

Generally, neutral olefin molecules and those olefin molecules containing moderately electron-donating or electron withdrawing groups, that give rise to fractional positive or negative charge to the double bond, favor free radical polymerization. Also, the molar volume of the lateral group of the monomer might decrease its reactivity. In the comonomer system studied, both GMA and MTM monomers consist of electron-withdrawing ester groups to which epoxy and thiophene rings are attached, respectively. Epoxy and thiophene ester groups weaken the electron density of the double bonds of the monomers through the carbonyl group. This group is polar due to the electrons forming the $\sigma$-bond, and particularly those forming the $\pi$-bond, are displaced toward oxygen bond, which is more electronegative than the carbon. On the other hand, both of the monomers possess a slightly electron-donating methyl group.

On the basis of the monomer feed ratios and the copolymer compositions, the monomer reactivity ra- tios of GMA and MTM were determined using the Fineman-Ross (FR) and the Kelen Tüdós (KT) graphical methods. ${ }^{28,29}$ The FR equation is one of the earliest attempts to linerize the copolymer composition. According to the FR method the monomer reactivity ratios can be obtained by equation:

$$
G=H r_{\mathrm{GMA}}-r_{\mathrm{MTM}}
$$

where the reactivity ratios, $r_{\mathrm{GMA}}$ and $r_{\mathrm{MTM}}$ correspond to the GMA and MTM monomers respectively. The parameters $\mathrm{G}$ and $\mathrm{H}$ are defined as follows:

$$
G=X(Y-1) / Y \quad \text { and } H=X^{2} / Y
$$

with

$$
X=M_{\mathrm{GMA}} / M_{\mathrm{MTM}} \quad \text { and } \quad Y=m_{\mathrm{GMA}} / m_{\mathrm{MTM}}
$$

$M_{\mathrm{GMA}}$ and $M_{\mathrm{MTM}}$ are the monomer molar compositions in feed and $m_{\mathrm{GMA}}$ and $m_{\mathrm{MTM}}$ the copolymer molar molar compositions. The FR plot is given in Figure 4.

Alternatively, the reactivity ratios can be obtained using the KT method which introduces new parameters into the linearized copolymerization equation:

$$
\eta=\left(r_{\mathrm{GMA}}+r_{\mathrm{MTM}} / \alpha\right) \xi-r_{\mathrm{MTM}} / \alpha
$$

where $\eta$ and $\xi$ are functions of the parameter $G$ and $H$ :

$$
\eta=G /(\alpha+H) \quad \text { and } \quad \xi=H /(\alpha+H)
$$




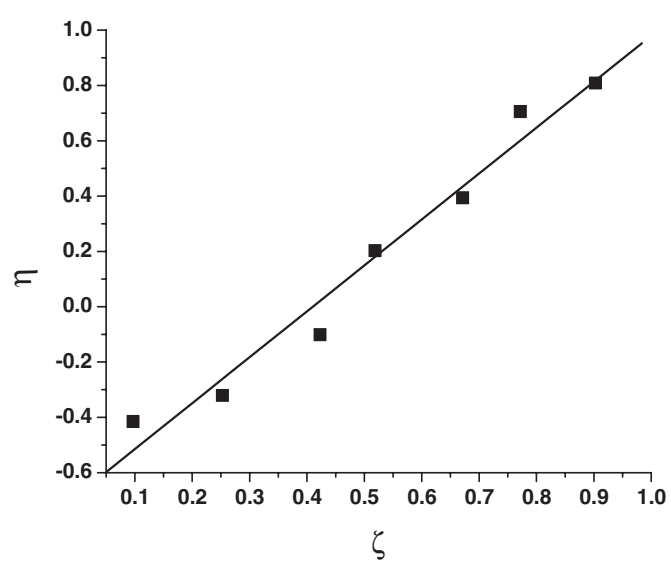

Figure 5. Kelen Tüdos plot for the GMA and MTM copolymer system.

and $\alpha$ a constant which is equal to $\left(H_{\max } \cdot H_{\min }\right)^{1 / 2}$. $H_{\max }$ and $H_{\min }$ are the highest and lowest values of $H$ from the series of measurements. From the linear plot of $\eta$ as a function of $\xi$, the values of $\eta$ for the intercept at $\xi=0$ and $\xi=1$ are used to calculate the reactivity ratios according to the equations:

$$
\xi=0 \Rightarrow \eta=-r_{\mathrm{MTM}} / \alpha \text { and } \xi=1 \Rightarrow \eta=r_{\mathrm{GMA}}
$$

The KT plot for low conversion data of this system is given in Figure 5. The copolymerizaiton data for both systems are provided in Table III.

The reactivity ratios of GMA and MTM determined from FR and KT methods are presented in Table IV. The value of $r_{\mathrm{GMA}}$ is almost equal to 1 and that of $r_{\mathrm{MTM}}$ is less than 1, which indicates the presence of a higher incorporation of GMA units in the copolymer than in the feed. This result can be interpreted in terms of the effect of the volume difference of epoxy and
Table III. FR and KT parameters for copolymerization of GMA with MTM

\begin{tabular}{ccccccc}
\hline Copolymer & $\mathrm{X}$ & $\mathrm{Y}$ & $\mathrm{G}$ & $\mathrm{H}$ & $\eta$ & $\xi$ \\
\hline 1 & 0.1644 & 0.2968 & -0.3895 & 0.0911 & -0.4148 & 0.0970 \\
2 & 0.3835 & 0.5129 & -0.3634 & 0.2865 & -0.3204 & 0.2526 \\
3 & 0.7173 & 0.8269 & -0.1501 & 0.6223 & -0.1021 & 0.4233 \\
4 & 1.1505 & 1.4502 & 0.3572 & 0.9128 & 0.2029 & 0.5185 \\
5 & 1.9180 & 2.1250 & 1.0154 & 1.7312 & 0.3937 & 0.6713 \\
6 & 3.4524 & 4.1556 & 2.6216 & 2.8688 & 0.7055 & 0.7718 \\
7 & 8.0498 & 8.2105 & 7.0694 & 7.8922 & 0.8089 & 0.9030 \\
$\alpha=0.8478$ & & & & & & \\
\hline \multicolumn{7}{l}{} \\
\end{tabular}

Table IV. Reactivity ratios

\begin{tabular}{cccc}
\hline Method & $r_{\mathrm{GMA}}$ & $r_{\mathrm{MTM}}$ & $r_{\mathrm{MTM}} r_{\mathrm{GMA}}$ \\
\hline FR & 0.9795 & 0.5641 & 0.5525 \\
KT & 0.9796 & 0.5771 & 0.5653 \\
\hline
\end{tabular}

thiophene rings and their contribution to the electron-withdrawing property of the carbonyl group. The reactivity ratios of the comonomer GMA-MTM also imply that GMA has almost the same reactivity toward GMA and MTM molecules, and the MTM propagating species react more toward GMA species than toward their own MTM monomer. On the other hand, the single parameter that can best describe the copolymer structure is the product of the reactivity ratios. The $r_{\mathrm{MTM}} r_{\mathrm{GMA}}$ values are less than 1, suggesting that there is a tendency for the formation of a random copolymer system.

In order to gain further information related to the copolymer structure, the statistical distribution of the sequences of two monomers (dyad) $M_{\mathrm{GMA}}-M_{\mathrm{GMA}}$, $M_{\mathrm{MTM}}-M_{\mathrm{MTM}}$ and $M_{\mathrm{GMA}}-M_{\mathrm{MTM}}$ were calculated employing the method proposed by Igarashi. ${ }^{30}$

$$
\begin{aligned}
& M_{\mathrm{GMA}}-M_{\mathrm{GMA}}=\phi_{\mathrm{GMA}}-\frac{2 \phi_{\mathrm{GMA}}\left(1-\phi_{\mathrm{GMA}}\right)}{1+\left[\left(2 \phi_{\mathrm{GMA}}-1\right)^{2}+4 r_{\mathrm{GMA}} r_{\mathrm{MTM}} \phi_{\mathrm{GMA}}\left(1-\phi_{\mathrm{GMA}}\right)\right]^{1 / 2}} \\
& M_{\mathrm{MTM}}-M_{\mathrm{MTM}}=\left(1-\phi_{\mathrm{GMA}}\right)-\frac{2 \phi_{\mathrm{GMA}}\left(1-\phi_{\mathrm{GMA}}\right)}{1+\left[\left(2 \phi_{\mathrm{GMA}}-1\right)^{2}+4 r_{\mathrm{GMA}} r_{\mathrm{MTM}} \phi_{\mathrm{GMA}}\left(1-\phi_{\mathrm{GMA}}\right)\right]^{1 / 2}} \\
& M_{\mathrm{GMA}}-M_{\mathrm{MTM}}=\frac{4 \phi_{\mathrm{GMA}}\left(1-\phi_{\mathrm{GMA}}\right)}{1+\left[\left(2 \phi_{\mathrm{GMA}}-1\right)^{2}+4 r_{\mathrm{GMA}} r_{\mathrm{MTM}} \phi_{\mathrm{GMA}}\left(1-\phi_{\mathrm{GMA}}\right)\right]^{1 / 2}}
\end{aligned}
$$

where $\phi_{\mathrm{GMA}}$ is the mole fraction of the GMA in the copolymer. The mean sequence lengths $\mu_{\mathrm{GMA}}$ and $\mu_{\text {MTM }}$ were also calculated using the following equations: ${ }^{31}$

$$
\begin{aligned}
& \mu_{\mathrm{GMA}}=1+r_{\mathrm{GMA}} \frac{\left[M_{\mathrm{GMA}}\right]}{\left[M_{\mathrm{MTM}}\right]} \\
& \mu_{\mathrm{MTM}}=1+r_{\mathrm{MTM}} \frac{\left[M_{\mathrm{MTM}}\right]}{\left[M_{\mathrm{GMA}}\right]}
\end{aligned}
$$

The data related to the dyad monomer sequences and mean sequence lengths are presented in Table V, whereas the plot in Figure 6 displays the variation of the dyad fractions with the GMA mole fraction in the copolymers. These results and those obtained from the determination of reactivity ratios using FR and KT methods complement each other and provide further insight into the copolymer structure.

There has been extensive study of the copolymeri- 
zation of GMA with acrylate or methacrylate type monomers bearing various functional side groups using conventional free radical polymerization in the literature. Some results are reviewed in Table VI. The published data reflect the effects of comonomer structure leading to different reactivity ratios. It should be also pointed out that a change of polymerization conditions such as different polymerization temperatures or polymerization media with different polarity leads to different reactivity ratio for even the same monomer pair.

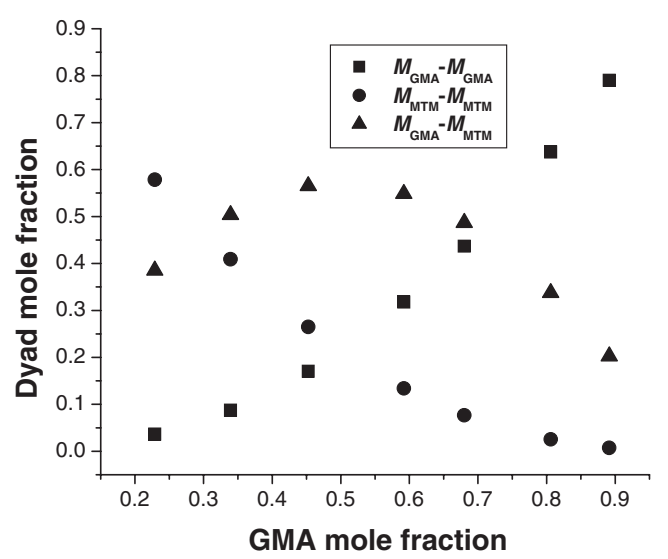

Figure 6. Dyad monomer sequence fractions $v s$ the GMA mole fractions for the copolymers.

\section{Thermal Analysis of the Copolymers}

Thermal behavior of the resulting copolymers were investigated by using DSC and TGA. DSC thermograms of poly $\left(\mathrm{GMA}_{23}-\mathrm{Co}-\mathrm{MTM}_{77}\right)$, poly $\left(\mathrm{GMA}_{59}-\mathrm{co}-\right.$ $\left.\mathrm{MTM}_{41}\right)$, and poly $\left(\mathrm{GMA}_{89}-\mathrm{co}-\mathrm{MTM}_{11}\right)$ are given in Figure 7. The $T_{\mathrm{g}}$ values of the homopolymers ${ }^{17,40}$ and copolymers are presented in Table VII. The high $T_{\mathrm{g}}$ value of both homo- and co-polymers is attributed to $\alpha$-methyl groups, which facilitate the chain entanglement. Differential scanning calorimetry thermograms of all copolymers show one glass transition at temperature intermediate between those of the relevant homopolymers, indicating the absence of formation of mixture of homopolymers or the formation of a block copolymer. The variation of $T_{\mathrm{g}}$ of copolymers with the mole fraction of GMA unit in the copolymer is shown in Figure 8. TGA results indicate that thermal stability of the copolymer increases with an increase in the MTM content in the copolymer.

The chemical structure and composition and the monomer sequence distributions of the copolymers influence the thermal properties. Several releationships have been employed to describe the effect of these parameters on the glass transition temperature of the copolymers. ${ }^{41}$ The simplest equation describing the effect of composition on $T_{\mathrm{g}}$ is the Gibbs-Di Marzio. ${ }^{42}$

Table V. Structural data for copolymers of GMA and MTM

\begin{tabular}{cccccc}
\hline Copolymer & $M_{\mathrm{GMA}}-M_{\mathrm{GMA}}$ & $M_{\mathrm{MTM}}-M_{\mathrm{MTM}}$ & $M_{\mathrm{GMA}}-M_{\mathrm{MTM}}$ & $\mu_{\mathrm{GMA}}$ & $\mu_{\mathrm{MTM}}$ \\
\hline 1 & 0.0363 & 0.5785 & 0.3853 & 1.16 & 4.51 \\
2 & 0.0875 & 0.4090 & 0.5034 & 1.38 & 2.50 \\
3 & 0.1702 & 0.2649 & 0.5649 & 1.70 & 1.80 \\
4 & 0.3176 & 0.1339 & 0.5485 & 2.13 & 1.50 \\
5 & 0.4367 & 0.0767 & 0.4867 & 2.88 & 1.30 \\
6 & 0.6373 & 0.0252 & 0.3374 & 4.38 & 1.17 \\
7 & 0.7902 & 0.0073 & 0.2025 & 8.88 & 1.07 \\
\hline
\end{tabular}

Table VI. Reactivity Ratios ${ }^{\mathrm{b}}$ of GMA with acrylate type monomers

\begin{tabular}{lllc}
\hline \multicolumn{1}{c}{ Comonomer } & $r_{\mathrm{GMA}}$ & $r_{\mathrm{COM}}{ }^{\mathrm{b}}$ & Reference \\
\hline 4-Nitrophenyl acrylate & 1.15 & 1.37 & 32 \\
4-Benzyloxycarbonylphenyl acrylate & 1.8741 & 0.4996 & 33 \\
3,5-Dimethylphenyl acrylate & 4.648 & 0.292 & 34 \\
Butyl acrylate & 2.16 & 0.083 & 35 \\
Methyl methacrylate & 0.934 & 0.726 & 35 \\
Butyl methacrylate & 0.94 & 0.85 & 35 \\
4-Propanoylphenyl methacrylate & 0.713 & 1.497 & 4 \\
4-Benzyloxycarbonylphenyl methacrylate & 0.8159 & 1.2099 & 36 \\
Phenacyl methacrylate & 1.32 & 1.45 & 37 \\
3,5-Dimethylphenyl methacrylate & 0.43 & 0.65 & 38 \\
4-Benzolyphenyl methacrylate & 0.712 & 1.411 & 39 \\
3-Methylthienyl methacrylate & 0.9796 & 0.5769 & present study \\
\hline
\end{tabular}

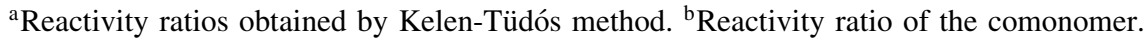




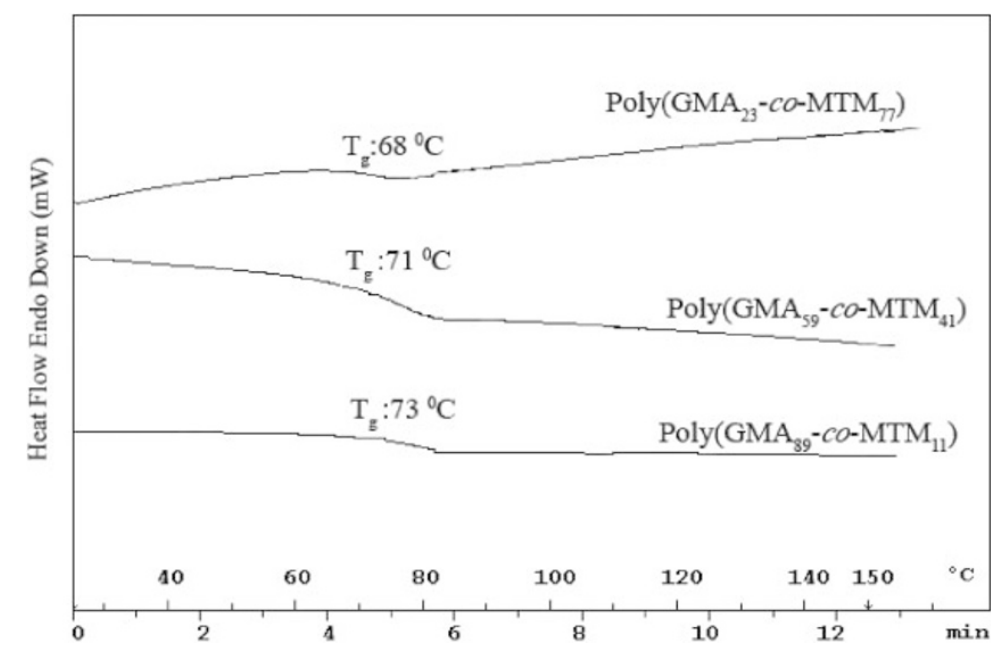

Figure 7. DSC thermograms of poly $\left(\mathrm{GMA}_{23}-c o-\mathrm{MTM}_{77}\right)$, poly $\left(\mathrm{GMA}_{59}-c o-\mathrm{MTM}_{41}\right)$ and poly $\left(\mathrm{GMA}_{89}-c o-\mathrm{MTM}_{11}\right)$.

Table VII. TGA and DSC data for GMA-MTM copolymer system

\begin{tabular}{lcccccc}
\hline \multicolumn{1}{c}{ Polymer } & $m_{\mathrm{GMA}}{ }^{\mathrm{a}}$ & $m_{\mathrm{MTM}}$ & $T_{\mathrm{g}}\left({ }^{\circ} \mathrm{C}\right)$ & $\mathrm{IDT}^{\mathrm{b}}\left({ }^{\circ} \mathrm{C}\right)$ & $T_{\mathrm{w} 10}{ }^{\mathrm{c}}\left({ }^{\circ} \mathrm{C}\right)$ & $T_{\mathrm{w} 90}{ }^{\mathrm{d}}\left({ }^{\circ} \mathrm{C}\right)$ \\
\hline PMTM & 0.0000 & 1.0000 & 65 & 245 & 297 & 448 \\
P(GMA-co-MTM) & 0.2289 & 0.7711 & 68 & 225 & 280 & 435 \\
& 0.3390 & 0.6610 & 69 & 220 & 275 & 432 \\
& 0.4535 & 0.5465 & 70 & 215 & 267 & 415 \\
& 0.5917 & 0.4083 & 71 & 211 & 265 & 417 \\
& 0.6800 & 0.3200 & 71 & 205 & 264 & 412 \\
PGMA & 0.8060 & 0.1940 & 72 & 202 & 254 & 405 \\
& 0.8915 & 0.1086 & 73 & 196 & 260 & 398 \\
\hline
\end{tabular}

${ }^{\mathrm{a}} m_{\mathrm{GMA}}$ is the mole fraction of GMA in the copolymer. ${ }^{\mathrm{b}} I D T$ is initial decomposition temperature.

${ }^{\mathrm{c}}$ Temperature at which the weight loss is $10 \%$. ${ }^{\mathrm{d}}$ Temperature at which the weight loss is $90 \%$.

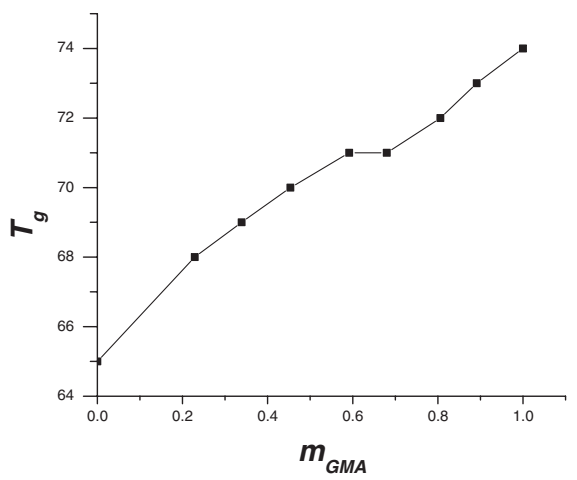

Figure 8. Variation of $T_{\mathrm{g}}$ with composition of poly(GMA-coMTM).

$$
T_{\mathrm{g}}=\phi_{\mathrm{GMA}} T_{\mathrm{gGMA}}+\phi_{\mathrm{MTM}} T_{\mathrm{gMTM}}
$$

where $\phi_{\mathrm{GMA}}$ and $\phi_{\mathrm{MTM}}$ are the mole fractions of GMA and MTM monomers respectively in the copolymer, whereas $T_{\mathrm{gGMA}}$ and $T_{\mathrm{gMTM}}$ are the glass transition temperatures of the two homopolymers, respectively.

A similar relationship was introduced by Fox. ${ }^{43}$
Table VIII. Glass transition temperatures for the copolymers

\begin{tabular}{ccccc}
\hline Copolymer & PGMA (wt. \%) & $T_{\mathrm{g}}\left({ }^{\circ} \mathrm{C}\right)^{\mathrm{a}}$ & $T_{\mathrm{g}}\left({ }^{\circ} \mathrm{C}\right)^{\mathrm{b}}$ & $T_{\mathrm{g}}\left({ }^{\circ} \mathrm{C}\right)^{\mathrm{c}}$ \\
\hline 1 & 18.38 & 68 & 67.1 & 66.5 \\
2 & 28.03 & 69 & 68.1 & 67.3 \\
3 & 38.55 & 70 & 69.1 & 68.2 \\
4 & 52.39 & 71 & 70.3 & 69.4 \\
5 & 61.72 & 71 & 71.1 & 70.3 \\
6 & 75.92 & 72 & 72.3 & 71.6 \\
7 & 86.17 & 73 & 73.0 & 72.6 \\
\hline
\end{tabular}

${ }^{\mathrm{a}}$ Experimental result by DSC measurements. ${ }^{\mathrm{b}}$ Theoretical prediction using the Giggs-Di Marzio equation eq 13. ${ }^{\mathrm{c}}$ Theoretical prediction using the Fox equation eq 14.

$$
\frac{1}{T_{\mathrm{g}}}=\frac{w_{\mathrm{GMA}}}{T_{\mathrm{gGMA}}}+\frac{w_{\mathrm{MTM}}}{T_{\mathrm{gMTM}}}
$$

where $w_{\mathrm{GMA}}$ and $w_{\mathrm{MTM}}$ are the weight fractions of GMA and MTM monomers in the copolymer. The experimental results related to $T_{\mathrm{g}}$ of the copolymers along with the predictions of the Gibbs-Di Marzio and Fox equations are presented in the Table VIII. 
The small deviations obtained from these two methods are attributed to the fact that both methods are based on only thermodynamic and free volume theories of the glass transition and they do not take into considereation the monomer sequence distribution and effect of their compatibility on steric and energetic interactions.

\section{CONCLUSIONS}

Copolymers of GMA and MTM were prepared by free radical solution polymerization using AIBN as an initiator at $60{ }^{\circ} \mathrm{C}$ and characterized by ${ }^{1} \mathrm{H}$ and ${ }^{13} \mathrm{C}$ NMR spectroscopic techniques. The values of polydispersity indices of copolymers suggested a tendency for chain termination by disproportionation. The monomer reactivity ratios of GMA and MTM were determined using the Fineman-Ross (FR) and the Kelen Tüdós (KT) graphical methods. The values of $r_{\mathrm{GMA}}$ from both methods were very close to 1 and $r_{\text {MTM }}$ values were less than 1 , which shows that the composition of GMA in the copolymer was greater than that in the feed. The product of the monomer reactivity ratios $r_{\mathrm{MTM}} r_{\mathrm{GMA}}<1$ suggests a distribution between alternating and ideal with a longer sequence of GMA units in the copolymer chain. The glass transition temperature of the copolymers increased with increase of GMA content. Thermogravimetric analysis showed that the thermal stability of the copolymers increased with the increase in the MTM content in the copolymer. In further studies GMA and MTM containing copolymers will be used in an electropolymerization process via thiophene units under anodic conditions to obtain a working electrode. Then, the resulting electrode will be employed in chemical immobilization of enzymes through epoxide rings as a biosensor application.

\section{REFERENCES}

1. A. Kraft, A. C. Grimsdale, and A. B. Holmes, Angew. Chem., Int. Ed., 37, 402 (1998).

2. J. G. Killian, B. M. Coffey, F. Gao, T. O. Pochler, and P. C. Searson, J. Electrochem. Soc., 143, 936 (1996).

3. N. Leventis, Polym. News, 20, 5 (1995).

4. U. Bulut, S. Alkan, F. Yilmaz, Y. Yagci, and L. Toppare, J. Macromol. Sci., Part A: Pure Appl. Chem., 41, 1 (2004).

5. U. Bulut, F. Yilmaz, Y. Yagci, and L. Toppare, React. Funct. Polym., 61, 63 (2004).

6. E. Unur, L. Toppare, Y. Yagci, and F. Yilmaz, J. Appl. Polym. Sci., 95, 1014 (2005).

7. J. N. Barisci, C. Conn, and G. G. Wallace, Trends Polym. Sci., 4, 307 (1996).

8. L. Olmeda, P. Hourquebie, and F. Jousse, Adv. Mater., 3, 373 (1993).

9. F. Beck and R. J. Michaelis, Coat. Technol., 64, 59 (1992).
10. M. A. Depoli, R. J. Waltman, A. F. Diaz, and J. Bargon, J. Polym. Sci., Polym. Chem. Ed., 23, 1687 (1985).

11. H. L. Wang, L. Toppare, and J. E. Fernandez, Macromolecules, 23, 1053 (1990).

12. F. Yilmaz, L. Cianga, Y. Guner, L. Topppare, and Y. Yagci, Polymer, 45, 5765 (2004).

13. F. Yilmaz, I. Cianga, K. Ito, T. Senyo, and Y. Yagci, Macromol. Rapid Commun., 24, 316 (2003).

14. a) P. Kovacic and M. B. Jones, Chem. Rev., 87, 357 (1987). b) A. O. Patil, A. J. Heeger, and F. Wudl, Chem. Rev., 88, 183 (1988).

c) J. R. Reynolds, Chemtech., 18, 440 (1988).

d) N. C. Billingham and P. D. Calvert, Adv. Polym. Sci., 90, 1 (1989).

e) J. Roncali, Chem. Rev., 97, 173 (1997).

15. P. Bauerle and S. Scheib, Adv. Mater., 5, 848 (1993).

16. F. Yilmaz, O. Sel, A. Cirpan, L. Toppare, Y. Hepuzer, and Y. Yagci, J. Macromol. Sci., Part A: Pure Appl. Chem., 41, 403 (2004).

17. F. Yilmaz, F. Kasapoglu, Y. Hepuzer, Y. Yagci, L. Toppare, E. G. Fernandes, and G. Galli, Des. Monomers Polym., 8, 223 (2005).

18. H. B. Yildiz, S. Kiralp, L. Toppare, F. Yilmaz, Y. Yagci, K. Ito, and T. Senyo, Polym. Bull., 53, 193 (2005).

19. D. A. Tirrell, in "Encyclopedia of Polymer Science and Engineering," 2nd ed., H. Mark, N. M. Bikales, C. G. Overberger, and G. Menges, Ed., John Wiley \& Sons, New York, 1985, vol. 4, p. 85.

20. J. Schaefer, Macromolecules, 2, 210 (1969).

21. a) A. S. Brar and A. Yadav, Polym. J., 35, 37 (2003).

b) A. S. Brar and T. Saini, Polym. J., 38, 1023 (2006).

c) R. Jayakumar, R. Balaji, and S. Nanjundan, Eur. Polym. J., 36, 1659 (2000).

22. G. G. Godwin, C. S. Jone Selvamalar, A. Pendilis, and S. Nanjundan, React. Funct. Polym., 59, 197 (2004).

23. J. J. Kalal, Polym. Sci., Polym. Sym. Edn., 62, 251 (1978).

24. H. Lee and K. Newille, "Handbook of Epoxy Resins," McGraw-Hill, New York, 1967.

25. J. Hardil and F. Svec, Angew. Makromol. Chem., 130, 81 (1985).

26. J. Lukas, F. Svec, and T. Kalal, J. Chromatogr., 153, 15 (1978).

27. S. Teramachi, A. Hasegawa, M. Akatsuka, A. Yamashita, and N. Takemoto, Macromolecules, 11, 1206 (1978).

28. M. Fineman and S. D. Ross, J. Polym. Sci., 5, 259 (1950).

29. T. Kelen, F. Tüdós, B. Turesanyi, and J. P. Kennedy, J. Polym. Sci., 15, 3041 (1977).

30. S. Igarashi, J. Polym. Sci., Polym. Lett. Ed., 1, 359 (1963).

31. H. G. Elias, in "Macromolecules," Plenum Press, New York, 1971, vol. 2, p. 761.

32. S. Thamizharasi, P. Gnanasundaram, and B. S. R. Reddy, J. Appl. Polym. Sci., 65, 1285 (1997).

33. C. S. Jone Selvamalar, P. S. Vijayanand, A. Penlidis, and S. Nanjundan, J. Appl. Polym. Sci., 91, 3604 (2004).

34. P. S. Vijayanand, R. Arunprasath, R. Balaji, and S. Nanjundan, J. Appl. Polym. Sci., 85, 2261 (2002).

35. "Polymer handbook," 4th ed., J. Bandrup, E. H. Immergut, and E. A. Grulke, Ed., Wiley Interscience, New York, 1999, Page II-226. 


\section{O. GUNAYDIN and F. YILMAZ}

36. C. S. Jone Selvamalar, T. Krithiga, A. Penlidis, and S. Nanjundan, React. Funct. Poylm., 56, 89 (2003).

37. C. Soykan, M. Ahmedzade, and M. Coskun, Eur. Polym. J., 36, 1667 (2000).

38. P. S. Vijayanand, S. Radhakrishman, R. Arun Prasath, and S. Nanjundan, Eur. Polym. J., 38, 1319 (2002).

39. S. Nanjundan, C. Sreekuttan Unnithan, C. S. Jone Selvamalar, and A. Penlidis, React. Funct. Polym., 62, 1 (2005).

40. "Polymer handbook," 4th ed., J. Bandrup, E. H. Immergut, and E. A. E. Grulke, Ed., Wiley Interscience, New York, 1999, Page VI-203.

41. a) M. Gordon and J. S. Taylor, J. Appl. Polym. Sci., USSA, 2, 492 (1952).

b) L. A. Wood, J. Polym. Sci., 28, 319 (1958).

c) R. Z. Couchman and F. R. Karasz, Macromolecules, 11, 117 (1978).

42. J. H. Gibbs and E. A. Di, J. Polym. Sci., Part A, 1, 1417 (1963).

43. T. G. Fox and P. J. Florry, J. Appl. Phys., 21, 581 (1950). 